\title{
A Facile Method of Preparing the Asymmetric Supercapacitor with Two Electrodes Assembled on a Sheet of Filter Paper
}

\author{
Shasha Jiao ${ }^{1}$, Tiehu Li ${ }^{1, *}$, Chuanyin Xiong ${ }^{2, *}$, Chen Tang ${ }^{1}$, Alei Dang ${ }^{1}{ }^{1}, \mathrm{Hao} \mathrm{Li}{ }^{1}$ and \\ Tingkai Zhao ${ }^{1}$ \\ 1 School of Materials Science and Engineering, Northwestern Polytechnical University, Xi'an 710072, China; \\ usershasha@sina.com (S.J.); mecdoll@yahoo.com (C.T.); dangalei@nwpu.edu.cn (A.D.); \\ lihao@nwpu.edu.cn (H.L.); ztk@nwpu.edu.cn (T.Z.) \\ 2 School of Materials Science and Engineering, Shaanxi University of Science and Technology, \\ $\mathrm{Xi}^{\prime}$ an 710072, China \\ * Correspondence: litiehu@nwpu.edu.cn (T.L.); xiongchuanyin@126.com (C.X.)
}

Received: 22 August 2019; Accepted: 16 September 2019; Published: 19 September 2019

check for updates

\begin{abstract}
An asymmetric supercapacitor was prepared on a sheet of filter paper with two modified surfaces acting as electrodes in $1 \mathrm{M}$ potassium hydroxide aqueous solution. By choosing carbon nanotubes and two different kinds of metal oxides (zinc oxide and ferro ferric oxide) as electrode materials, the asymmetric supercapacitor was successfully fabricated. The results showed that this device exhibited a wide potential window of $1.8 \mathrm{~V}$ and significantly improved electrochemical performances of its counterparts. Particularly, the one-sheet asymmetric supercapacitor demonstrated high energy density of $116.11 \mathrm{~W} \mathrm{~h} / \mathrm{kg}$ and power density $27.48 \mathrm{~kW} / \mathrm{kg}$, which was attributed to the combined action and shortened distance between the two electrodes, respectively. Besides, it showed superior electrochemical cycling stability with $87.1 \%$ capacitance retention under room temperature. These outstanding results can not only give researchers new insights into compact energy storage systems, but they also provide a good prospect for flexible asymmetric supercapacitors.
\end{abstract}

Keywords: carbon nanotubes; metal oxide; zinc oxide; ferroferric oxide; asymmetric supercapacitor

\section{Introduction}

With the exhaustion of fossil fuels and the growing emphasis on environmental pollution problems, in recent years, it has become urgent to find a perfect source of alternative energy. Supercapacitors, which help bridge the gap between conventional capacitors and batteries in energy and power densities, have been drawing much attention due to the excellent performances and various promising potential applications [1-4]. Naturally, large supercapacitors are often used for backup power sources of regenerative hybrid electric vehicles because of their quick charging and long cycling life. Moreover, the fast development of intelligent and smart materials have contributed significantly to the application of supercapacitors in various fields, such as medical treatment, wearable technology, military devices and so on [5-9]. Generally, according to the different energy storage mechanisms, supercapacitors can be divided into two groups: Electrical double layer capacitance (EDLC) and pseudo-capacitance [10-12]. For the former, energy storage depends on the adsorbed ion by electrostatic charge between the electrode/electrolyte interface. However, the pseudo-capacitance is based on the redox reaction of active materials on the electrode surface. There are three types of electrode materials for supercapacitors, which mainly include high surface area activated carbons, transition metal oxides and conductive polymers [13-16]. Currently, in order to improve energy density and power density, hybrid supercapacitor devices have been widely studied by researchers from home and 
abroad, for carrying both the merits of EDLC and pseudo-capacitance [17-19]. In addition, according to the formula of energy density for supercapacitors, $\mathrm{E}=\frac{1}{2} \mathrm{CV}^{2}$, it can be deduced that energy density is determined by specific capacitance $(\mathrm{C})$ and the potential window $(\mathrm{V})$. With large capacitance and potential window, it is clear to see that the energy density of the supercapacitor will definitely grow. Therefore, the preparation of asymmetric supercapacitors (AS) is also a promising approach to improve the electrochemical properties greatly in the same electrolyte [20-22]. The reason for this is that the AS can effectively increase the maximum operation voltage benefited from the different potential windows of electrodes, thus resulting in an increased specific capacitance and a high energy density.

Compared with the conventional carbon-based materials, carbon nanotubes (CNTs) show some special properties such as high surface area, strong absorbability and good electrical conductivity, which have been widely used in the research of EDLCs. Recently, many efforts have been devoted to the progress of CNTs in hybrid supercapacitor applications [15,23]. To sum up, the common types of CNT based composite electrode materials can be roughly divided into the following three categories: $\mathrm{CNTs} /$ metal composites, CNTs/metal oxide composites and CNTs/conductive polymer composites, respectively $[11,23-26]$.

Zinc oxide $(\mathrm{ZnO})$ is a kind of typical semiconductor with interesting piezoelectric, optoelectronic, and pyroelectric properties, which has been used extensively for optoelectronic devices, solid state gas sensors, production of green-blue ultraviolet, light emitting diodes and thin planar waveguides [27-29]. Recently, literature related to the suitability of $\mathrm{ZnO}$ as a potential candidate for supercapacitor has been gradually reported. Lo et al. successfully synthesized the $\mathrm{ZnO} / \mathrm{Ni}(\mathrm{OH})_{2}$ nanocomposite under optimal pulse electrodeposition conditions. The results exhibited a large specific capacitance of $1830 \mathrm{~F} / \mathrm{g}$, a high energy density of $51.5 \mathrm{~W} \mathrm{~h} / \mathrm{kg}$, and a high power density of $9 \mathrm{~kW} / \mathrm{kg}$, respectively [30]. In view of the low cost, facile preparation, environmental friendliness and other unique characteristics, ferroferric oxide $\left(\mathrm{Fe}_{3} \mathrm{O}_{4}\right)$ was extensively applied in many fields, such as microwave absorption, catalyst carrier, energy storage, sensing agent, magnetic recording and drug loading/delivery [31,32], etc. So far there is a growing concern over the possibility of $\mathrm{Fe}_{3} \mathrm{O}_{4}$ as electrode materials for supercapacitors and batteries due to the high theoretical capacity of its excellent electrochemical properties. Xia et al. reported high-quality mesoporous $\mathrm{Fe}_{3} \mathrm{O}_{4}$ nanocages as anode material for rechargeable lithium-ion batteries prepared by a complex-coprecipitation methods [33]. The unique anode demonstrated high specific capacitance and superior cycling performances at high and low current rates. Sun et al. fabricated a $\mathrm{Fe}_{3} \mathrm{O}_{4} / \mathrm{Fe}-\mathrm{CNTs}$ nanocomposite as electrode materials for supercapacitors at room temperature with a new chemical synthesis route. The as-prepared $\mathrm{Fe}_{3} \mathrm{O}_{4} / \mathrm{Fe}-\mathrm{CNTs}$ composite displayed a high specific capacitance of $1065 \mathrm{~F} / \mathrm{g}$ at the current density of $1 \mathrm{~A} / \mathrm{g}$, which maintained $88 \%$ of the initial value after 1000 cycles [34].

In recent years, flexible electronics have attracted widespread attention with the development of smart materials. It not only has excellent mechanical properties but also enables them to be bended easily and mounted on various surfaces. Therefore, it is vital to explore substrate materials for batteries and supercapacitors with high flexibility. Among a long list of flexible substrate candidates, filter paper can serve as both flexible substrate and a separator of the supercapacitor due to the notable properties of its ability to bend without breaking and its particular network structure of sufficient porosity to let the electrolyte pass through totally between two electrodes [35-39].

Herein, this paper developed a novel AS with two electrodes assembled on a sheet of filter paper only by a kind of simpler method. Through designing an asymmetric device, the potential window of the AS was enlarged. The energy and power densities increased accordingly. In addition, this study also discussed the composition, microstructure, morphological characteristics and electrochemical properties of the as-synthesized electrode and AS materials. The results provided an innovative idea and unique technique for fabricating high performances of AS. Furthermore, the achievements will lay a foundation for the development and improvement of flexible energy storage system. 


\section{Materials and Methods}

\subsection{Materials}

CNTs were procured by Beijing Chemical Works, Beijing, China and the purity was greater than 95\%. In order to get more functional groups, the raw CNTs were pre-acidated by strong acid treatment. Filter paper (FP), potassium hydroxide $(\mathrm{KOH}), 98 \%$ concentrated sulfuric acid $\left(\mathrm{H}_{2} \mathrm{SO}_{4}\right)$ and $68 \%$ concentrated nitric acid $\left(\mathrm{HNO}_{3}\right)$ were purchased from Xi'an Sanpu Fine Chemical Factory, Xi'an, China. Further, $\mathrm{Fe}_{3} \mathrm{O}_{4}$ and $\mathrm{ZnO}$ were purchased Sinopharm Chemical Reagent Co. Ltd., China. All materials were commercially available and used as received.

\subsection{Preparation of Flexible AS on One-Sheet of FP}

Firstly, the raw CNTs underwent a treatment with concentrated $\mathrm{H}_{2} \mathrm{SO}_{4}$ and $\mathrm{HNO}_{3}$ to improve their suspension in water. Subsequently, $20 \mathrm{mg}$ of CNTs were added in $50 \mathrm{~mL}$ deionized water by stirring and ultrasonic dispersing to obtain highly water-dispersible and an equably distributed CNT mixture. This method works the same for preparing $50 \mathrm{~mL} \mathrm{ZnO}$ suspension $(3 \mathrm{mg} / \mathrm{mL})$. Following that, based on the vacuum filtration technology, CNTs and $\mathrm{ZnO}$ were successively deposited on FP through controlling filtration suction time and pressure. After being dried in the air, the flexible $\mathrm{ZnO} / \mathrm{CNT} / \mathrm{FP}$ electrode was successfully fabricated. The procedures for preparation of $\mathrm{Fe}_{3} \mathrm{O}_{4} / \mathrm{CNT} / \mathrm{FP}$ film was similar to that of $\mathrm{ZnO} / \mathrm{CNT} / \mathrm{FP}$ except for the suspension of $\mathrm{Fe}_{3} \mathrm{O}_{4}(2 \mathrm{mg} / \mathrm{mL})$. Finally, the FP was coated with CNTs and $\mathrm{ZnO}$ on one side, while CNTs and $\mathrm{Fe}_{3} \mathrm{O}_{4}$ were deposited on the other side. Five samples of AS were prepared to investigate performance. Figure 1 illustrates the schematic diagram of the preparation process.

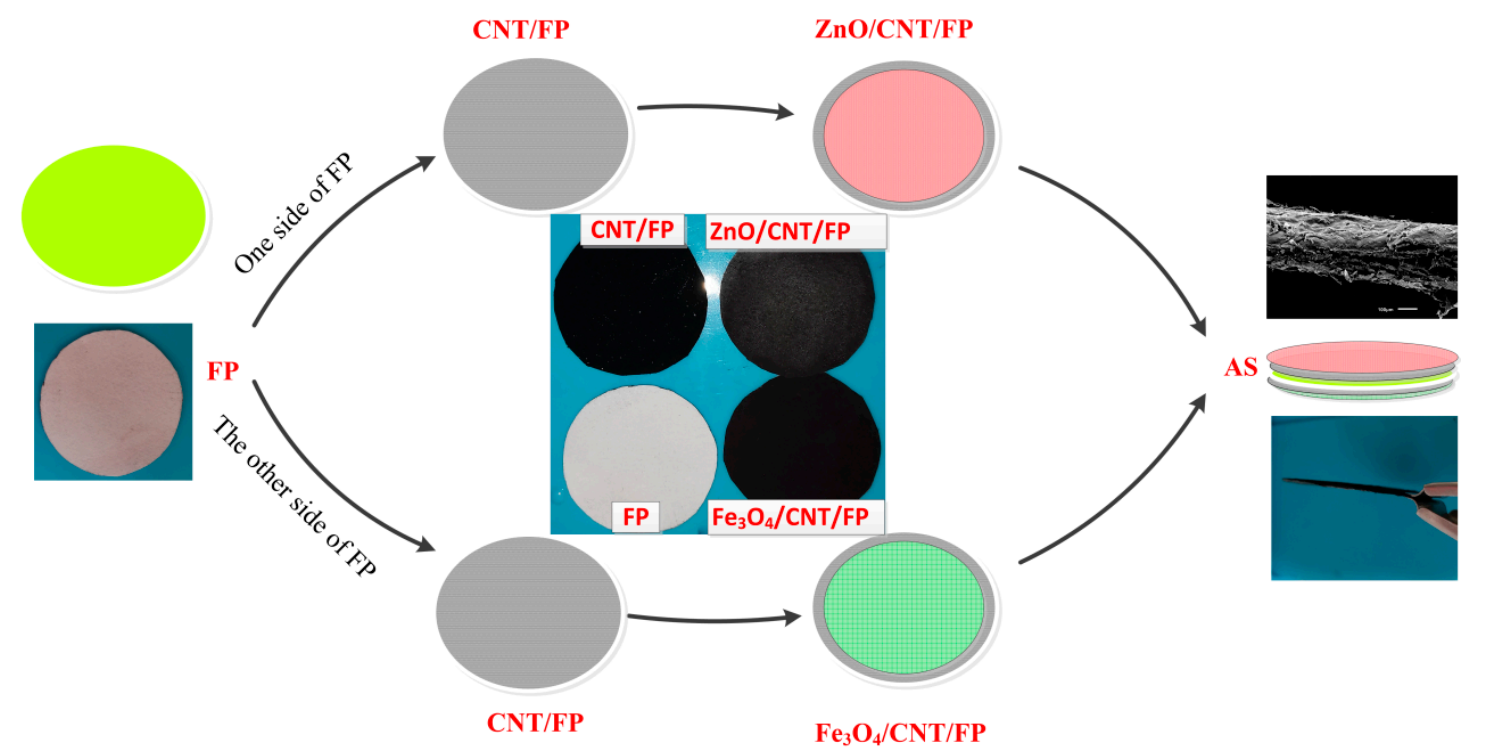

Figure 1. Schematic diagram of the preparing process of zinc oxide $(\mathrm{ZnO}) /$ carbon nanotubes $(\mathrm{CNT}) /$ filter paper (FP), $\mathrm{Fe}_{3} \mathrm{O}_{4} / \mathrm{CNT} / \mathrm{FP}$ and asymmetric supercapacitors (AS) on one sheet of FP, respectively.

It is critically important to evaluate the mass of active materials deposited on each side of FP. Based on the charge balance strategy $Q_{+}=Q_{-}$, the optimal mass ratio was calculated by the following equations below:

$$
\begin{aligned}
& \mathrm{Q}_{+}=\mathrm{C}_{+} \bullet \Delta \mathrm{E}_{+} \bullet \mathrm{m}_{+} \\
& \mathrm{Q}_{-}=\mathrm{C}_{-} \bullet \Delta \mathrm{E}_{-} \bullet \mathrm{m}_{-}
\end{aligned}
$$

where $Q_{+}$and $Q_{-}$are the stored charges on the positive and negative electrodes, respectively. $\Delta E_{+}$and $\Delta \mathrm{E}_{-}$relate to the potential ranges of each electrode. Where $\mathrm{C}_{+}$and $\mathrm{C}_{-}$are the specific capacitance of 
the positive and negative electrodes, respectively. $m_{+}$and $m_{-}$are the mass of electroactive materials on the electrodes $[40,41]$. Therefore, the optimal mass ratio $\left(m_{+}: m_{-}\right)$is obtained by the formula below:

$$
\frac{\mathrm{m}_{+}}{\mathrm{m}_{-}}=\frac{\mathrm{C}_{-} \bullet \Delta \mathrm{E}_{-}}{\mathrm{C}_{+} \bullet \Delta \mathrm{E}_{+}}
$$

Combined with the equation for calculating the specific capacitance $\left(C_{m}\right)$ below, the optimal mass ratio of positive electrode to negative one was 0.3125 :

$$
\mathrm{C}_{\mathrm{m}}=\frac{1}{\mathrm{~m} \bullet \gamma \bullet \Delta \mathrm{V}} \int_{\mathrm{V}_{0}}^{\mathrm{V}_{0}+\Delta \mathrm{V}} \mathrm{IdV}
$$

where $\mathrm{m}$ is the mass of active materials, $\gamma$ represents the scanning rate, I indicates the current response, $\Delta \mathrm{V}$ is the operating potential window, and $\mathrm{V}$ is the voltage, respectively. Besides, the corresponding energy density $(\mathrm{E})$ and power density $(\mathrm{P})$ can be obtained by the following formulas [42]:

$$
\begin{gathered}
\mathrm{E}=\frac{\mathrm{C}_{\mathrm{m}} \bullet \mathrm{V}^{2}}{2} \\
\mathrm{P}=\frac{\mathrm{E}}{\mathrm{t}}
\end{gathered}
$$

where $C_{m}$ is the specific capacitance, $V$ denotes the potential window and $t$ stands for the discharging time.

\subsection{Characterization and Electrochemical Measurements}

The chemical compositions and morphology of the samples were examined by X-ray diffraction (XRD; Cu-K $\alpha \lambda=1.541 \AA, 2 \theta=10 \sim 80^{\circ}$ ), Raman spectroscope (Raman spectrometer Labram ARAMIS, HR800, Jobin Yvon LabRam, Japan ), field-emission scanning electron microscopy (FE-SEM; Hitachi S-5200, Japan), and high-resolution electron scanning microscopy (HRTEM, JEM2100, JEOL, Japan). An electrochemical workstation (CHI 660D) was employed to test the electrochemical performances of the composites by using $1 \mathrm{M} \mathrm{KOH}$ solution as electrolyte at room temperature.

\section{Results and Discussion}

\subsection{Structure and Morphology}

The XRD patterns of $\mathrm{ZnO} / \mathrm{CNT} / \mathrm{FP}, \mathrm{Fe}_{3} \mathrm{O}_{4} / \mathrm{CNT} / \mathrm{FP}$ and $\mathrm{ZnO} / \mathrm{CNT} / \mathrm{FP} / / \mathrm{Fe}_{3} \mathrm{O}_{4} / \mathrm{CNT} / \mathrm{FP}$ composites are presented in Figure 2a. Typically, for $\mathrm{CNT} / \mathrm{Fe}_{3} \mathrm{O}_{4} / \mathrm{FP}$, there were diffraction peaks around $30.3^{\circ}$, $35.7^{\circ}, 43.3^{\circ}, 54.1^{\circ}, 57.4^{\circ}$ and $62.9^{\circ}$, well corresponding to the diffraction characteristics of cubic $\mathrm{Fe}_{3} \mathrm{O}_{4}$ [43]. However, diffraction peaks located at $2 \theta$ around $31.6^{\circ}, 34.5^{\circ}, 36.2^{\circ}, 47.4^{\circ}, 56.5^{\circ}, 62.8^{\circ}$, $68.1^{\circ}$ and $69.3^{\circ}$ of $\mathrm{ZnO} / \mathrm{CNT} / \mathrm{FP}$ hybrid suggested (100), (001), (101), (102), (110), (103) (112) and (201) lattice planes of $\mathrm{ZnO}$, respectively [44-46]. Furthermore, the composites deposited on both sides of the same FP were also observed. A strong peak was clearly observed from the XRD curve of $\mathrm{ZnO} / \mathrm{CNT} / \mathrm{FP} / / \mathrm{Fe}_{3} \mathrm{O}_{4} / \mathrm{CNT} / \mathrm{FP}$ hybrid, which was the same case with $\mathrm{ZnO} / \mathrm{CNT} / \mathrm{FP}$ and $\mathrm{Fe}_{3} \mathrm{O}_{4} / \mathrm{CNT} / \mathrm{FP}$ electrodes. The reason for this was attributed to the diffraction characteristics of $C N T$. The XRD results of $\mathrm{ZnO} / \mathrm{CNT} / \mathrm{FP} / / \mathrm{Fe}_{3} \mathrm{O}_{4} / \mathrm{CNT} / \mathrm{FP}$ showed that the distinct peaks of $\mathrm{CNT}$, $\mathrm{ZnO}$ and $\mathrm{Fe}_{3} \mathrm{O}_{4}$ were found on the intensity curve of one sheet FP composite. The structural characteristics of the as-prepared electrodes and AS were further determined by Raman spectra. As illustrated in Figure 2b, two typical Raman peaks existed in the Raman spectroscopy, indicating D and G bands of CNT in the composites of the test samples, which approved the results of the above-mentioned XRD analysis. 

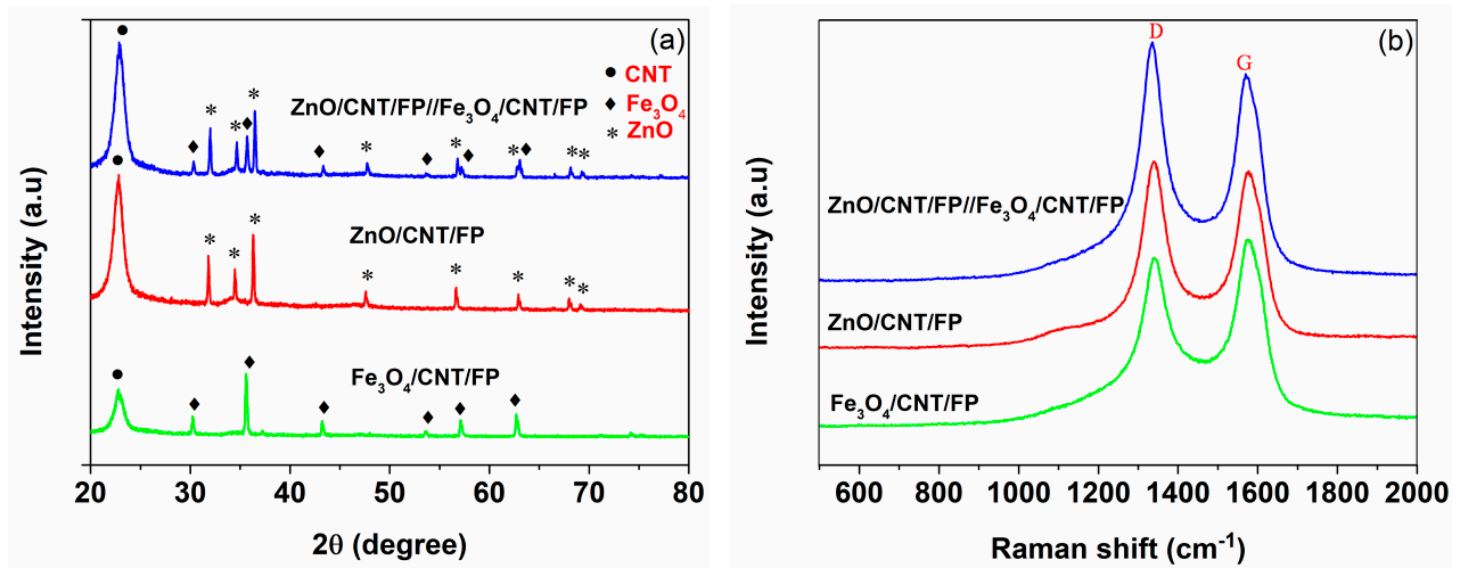

Figure 2. (a) XRD patterns of $\mathrm{ZnO} / \mathrm{CNT} / \mathrm{FP}, \mathrm{Fe}_{3} \mathrm{O}_{4} / \mathrm{CNT} / \mathrm{FP}$ and $\mathrm{ZnO} / \mathrm{CNT} / \mathrm{FP} / \mathrm{Fe}_{3} \mathrm{O}_{4} / \mathrm{CNT} / \mathrm{FP}$ composites, respectively; (b) Raman spectra of $\mathrm{ZnO} / \mathrm{CNT} / \mathrm{FP}, \quad \mathrm{Fe}_{3} \mathrm{O}_{4} / \mathrm{CNT} / \mathrm{FP}$ and $\mathrm{ZnO} / \mathrm{CNT} / \mathrm{FP} / / \mathrm{Fe}_{3} \mathrm{O}_{4} / \mathrm{CNT} / \mathrm{FP}$ composites, respectively.

The surface and section morphology images of AS are displayed in Figure 3. Figure 3a-d display the micrographs of the $\mathrm{ZnO} / \mathrm{CNT} / \mathrm{FP}$ composite. As illustrated in Figure $3 \mathrm{a}$, b, the fiber skeleton of FP was uniformly deposited with a solid and continuous layer of CNTs and grain growth of $\mathrm{ZnO}$, which can improve the electrochemical activity of the FP substrate. At high magnification, microstructure investigation of Figure $3 \mathrm{c}$ clearly showed that the white $\mathrm{ZnO}$ nanocrystals were anchored onto a nest-like pattern of CNTs with three dimensional porous FP as a support, consisting with the XRD and Raman results. Figure 3d displayed the $\mathrm{ZnO}$ nanoparticles by the HRTEM image. Furthermore, the surface structures of the $\mathrm{Fe}_{3} \mathrm{O}_{4} / \mathrm{CNT} / \mathrm{FP}$ composite electrode were also obtained by SEM. Figure $3 \mathrm{e}, \mathrm{f}$ displays the representative images of $\mathrm{Fe}_{3} \mathrm{O}_{4} / \mathrm{CNT} / \mathrm{FP}$ film under different magnifications. As shown in Figure 3e, the surface of the three-dimensional cellulose FP was covered with a dense and continuous layer of substances. It was illustrated clearly in Figure $3 \mathrm{f}$, g that the fine particles of $\mathrm{Fe}_{3} \mathrm{O}_{4}$ were uniformly distributed throughout the interior and surface of the FP. In addition, further observation was performed to reveal the details about the surface of the $\mathrm{Fe}_{3} \mathrm{O}_{4} / \mathrm{CNT} / \mathrm{FP}$ film. Figure $3 \mathrm{~h}$ displays the cubic structure of $\mathrm{Fe}_{3} \mathrm{O}_{4}$ and entangled tube-shaped CNT, making the electrode a better electrochemical activation. Further, the fracture surface of AS studied by SEM images in Figure 3i shows a 3D porous structure sandwiched between two electrode materials, which made it a unitized configuration of electrodes and separator assembled on a piece of FP. I indicated that the average thickness of the as-synthesized AS sheet was around $150 \mu \mathrm{m}$; this being much thinner and lighter than most supercapacitors. 

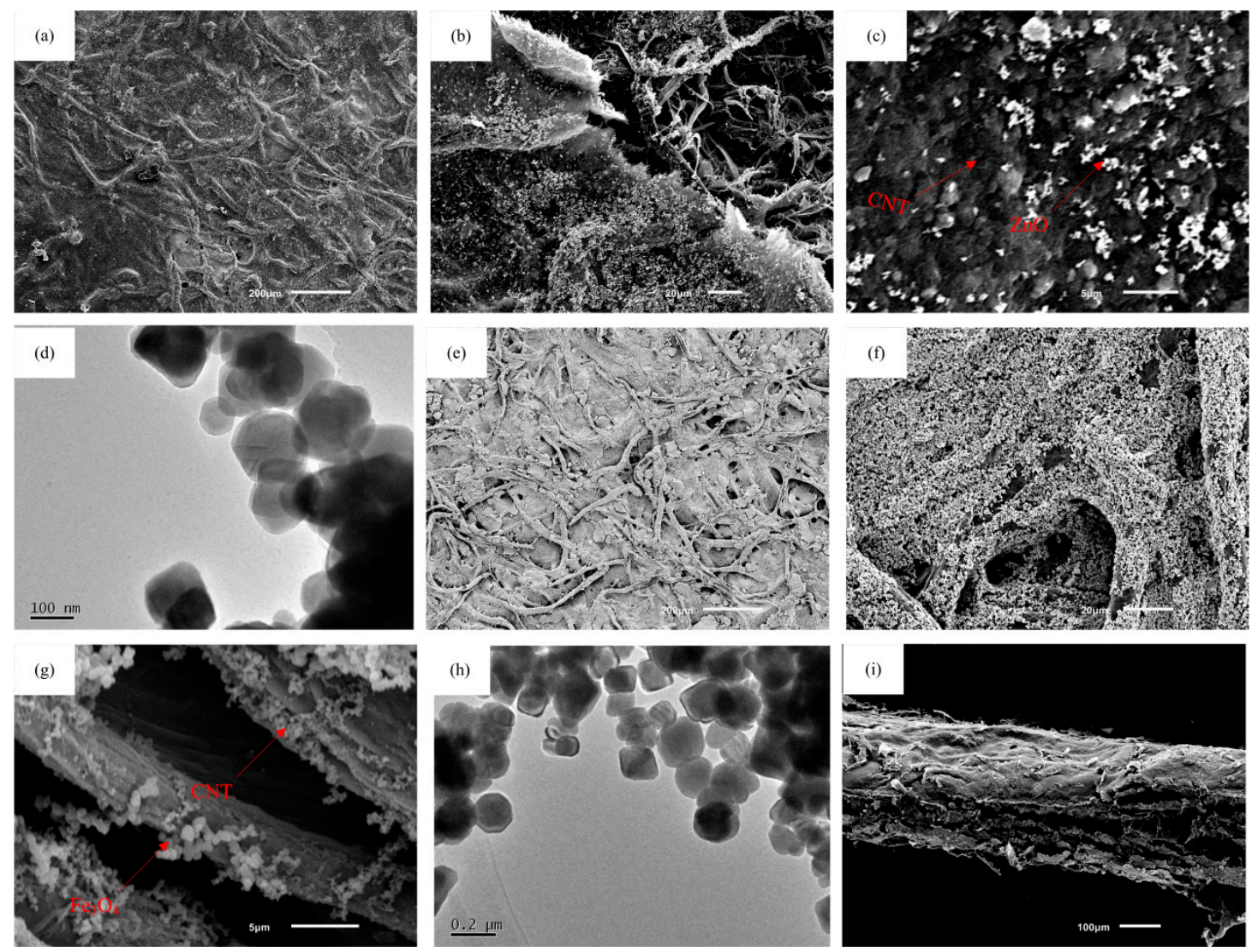

Figure 3. (a) Low power of the surface morphology image of the ZnO/CNT/FP electrode; (b) SEM image of the cellulose fiber of the $\mathrm{ZnO} / \mathrm{CNT} / \mathrm{FP}$ electrode; (c) high power image of the $\mathrm{ZnO} / \mathrm{CNT} / \mathrm{FP}$ electrode; (d) TEM image of the $\mathrm{ZnO} / \mathrm{CNT} / \mathrm{FP}$ electrode; (e) low power of the surface morphology image of the $\mathrm{Fe}_{3} \mathrm{O}_{4} / \mathrm{CNT} / \mathrm{FP}$ electrode; (f) SEM image of the cellulose fiber of the $\mathrm{Fe}_{3} \mathrm{O}_{4} / \mathrm{CNT} / \mathrm{FP}$ electrode; (g) high power image of the $\mathrm{Fe}_{3} \mathrm{O}_{4} / \mathrm{CNT} / \mathrm{FP}$ electrode; (h) TEM image of the $\mathrm{Fe}_{3} \mathrm{O}_{4} / \mathrm{CNT} / \mathrm{FP}$ electrode; (i) section morphology images of the AS.

\subsection{Electrochemical Tests of the As-Prepared Electrodes and AS}

The as-prepared $\mathrm{ZnO} / \mathrm{CNT} / \mathrm{FP}$ and $\mathrm{Fe}_{3} \mathrm{O}_{4} / \mathrm{CNT} / \mathrm{FP}$ films were systematically investigated in an aqueous solution of $\mathrm{KOH}(1 \mathrm{M})$. A conventional three-electrode system with each sample as a working electrode, $(\mathrm{Ag} / \mathrm{AgCl}$ as a reference electrode and platinum plate as a counter electrode), were applied to measure the electrochemical performances, respectively. A comparison of the potential range determined by cyclic voltammetry $(\mathrm{CV})$ results in Figure 4a indicated the optimized stable potential window of $\mathrm{ZnO} / \mathrm{CNT} / \mathrm{FP}$ was $0-0.8 \mathrm{~V}$ (vs. $\mathrm{Ag} / \mathrm{AgCl}$ ), while that of $\mathrm{Fe}_{3} \mathrm{O}_{4} / \mathrm{CNT} / \mathrm{FP}$ was $-1.0-0 \mathrm{~V}$ (vs. $\mathrm{Ag} / \mathrm{AgCl}$ ) under the same scanning rate of $50 \mathrm{mV} / \mathrm{s}$. According to experimental results of the $\mathrm{CV}$ test under different scan rates, the $\mathrm{CV}$ curves of $\mathrm{ZnO} / \mathrm{CNT} / \mathrm{FP}$ nanosheet demonstrated in Figure $4 \mathrm{~b}$ had a pair of symmetrical and steady peaks and a relatively closed area, revealing the large peak current values, which showed that the electrochemical reversibility and activity of ZnO/CNT/FP were good. These results were attributed to the electrochemically active layer of nanocrystalline $\mathrm{ZnO}$ and nano-scale particles of $\mathrm{CNT}$ of the $\mathrm{CNT} / \mathrm{ZnO} / \mathrm{FP}$ electrode, which enhanced the specific capacitance through a combination of metal oxide and carbon nanomaterials with the electrolyte. Meanwhile, as shown in Figure 4c, the shape of the CV curves of $\mathrm{Fe}_{3} \mathrm{O}_{4} / \mathrm{CNT} / \mathrm{FP}$ revealed that the capacitance characteristics were different from that of CNTs, the shape of which was typically an ideal rectangle, thereby indicating that $\mathrm{Fe}_{3} \mathrm{O}_{4}$ nanoparticles mainly provided the pseudo-capacitance effect on the composite electrode material. It was also noted that the current reactions changed along with the increase of scanning rates, but this was not exactly linear. Galvanostatic charge/discharge (GCD) 
tests of $\mathrm{ZnO} / \mathrm{CNT} / \mathrm{FP}$ and $\mathrm{Fe}_{3} \mathrm{O}_{4} / \mathrm{CNT} / \mathrm{FP}$ composite electrodes were conducted in $1 \mathrm{M} \mathrm{KOH}(\mathrm{aq})$ at various current densities of 1,2 and $5 \mathrm{~A} / \mathrm{g}$, respectively. The plots of voltage versus time corresponding to the results of the two electrodes are shown in Figure $4 \mathrm{~d}$,e. It can be concluded from these plots that the discharge time increased with the decrease of current density. Even if the minimum current density was $1 \mathrm{~A} / \mathrm{g}$, the charge and discharge time in all of the prepared films was only around $10 \mathrm{~s}$. Moreover, the relationships between the potential and the charge or discharge time was not accurately linear in the GCD curves. There were a few minor deviations from a straight line, which indicated the pseudocapacitive behaviors of the electrode material in the energy storage mechanism. Besides, because of the resistance of the electrode materials, the charge time of the sample was a little bit longer than the discharge time during cycling. On the other hand, the charging and discharging curves were nearly symmetric, demonstrating a reversible electrochemical behavior resulted from the introduction of CNT, which had more comparative advantages of the double layer capacitor effect. Moreover, electrochemical impedance spectroscopy measurements were also carried out to further illustrate the performances of electrode nanocomposites. It is displayed in Figure $4 \mathrm{f}$ that the resistance of electrode-electrolyte interfaces $\left(R_{s}\right)$ of the two electrodes were 2.5 and $2.6 \Omega$, respectively, which were determined by the high-frequency intercept on the $X$-axis. The diameter of the semicircle in the lower-left corner of Figure $4 \mathrm{f}$ represented the charge transfer resistance of electrode $\left(R_{\mathrm{ct}}\right)$, while the steep straight line at the low frequency showed an excellent ion diffusion behavior in the electrolyte. According to the figures given below, it was obvious that each electrode exhibited a certain similarity of lower $R_{\mathrm{s}}$ and $\mathrm{R}_{\mathrm{ct}}$ values, indicating a competitive candidate in terms of high capacity and good cycle stability.

As displayed in Figure $5 \mathrm{a}$, the $\mathrm{CV}$ curves of $\mathrm{ZnO} / \mathrm{CNT} / \mathrm{FP} / \mathrm{Fe}_{3} \mathrm{O}_{4} / \mathrm{CNT} / \mathrm{FP}$ AS operated at different scanning speeds ranging from 5 to $100 \mathrm{mV} / \mathrm{s}$ with the potential window of $1.8 \mathrm{~V}$. The shape of the $\mathrm{CV}$ curves were well maintained without observation of any deformation even at the highest speed case of $100 \mathrm{mV} / \mathrm{s}$, suggesting the outstanding rate capability of the device. Moreover, it can be seen from the curves of Figure $5 \mathrm{a}$ that a couple of suspected redox peaks around $0.2 \mathrm{~V}$ and $0.4 \mathrm{~V}$ were also observed and shifted positively with the increasing scanning speed. Obviously, the relationship between the current response and potential response was not linear, which was totally different from the electric double layer capacitors. This fully indicated by the faradic pseudo-capacitance of the AS. In addition, the CV curves demonstrated a typical characteristic of hybrid AS at different scanning rates, which was the result of combining the actions of EDLC and faradic behaviors. Subsequently, its electrochemical properties were evaluated by GCD measurements at various current densities of 1,2 and $5 \mathrm{~A} / \mathrm{g}$, respectively. It is shown in Figure $5 b$ that the typical triangular shape of GCD curves indicated an approximate linear relationship of voltage versus time, demonstrating excellent capacitive behavior in agreement with the results from the CV test above. Besides, the specific capacitances, energy densities and power densities of AS device were calculated at the current densities of 1,2 and $5 \mathrm{~A} / \mathrm{g}$ based on the relevant formulas and GCD curves, respectively. The calculated value of $\mathrm{C}_{\mathrm{m}}, \mathrm{E}$ and $\mathrm{P}$ were listed and described in Table 1. The most significant improvement was that the $\mathrm{ZnO} / \mathrm{CNT} / \mathrm{FP} / \mathrm{Fe}_{3} \mathrm{O}_{4} / \mathrm{CNT} / \mathrm{FP}$ AS which exhibited remarkable energy/power densities which were superior to some of their normal types of counterparts. The first reason was the presence of the asymmetric configuration of the supercapacitor. Besides, the synergetic effect of electrode materials with nano/micro hierarchical structures (CNT, ZnO and $\mathrm{Fe}_{3} \mathrm{O}_{4}$ ) effectively increased the high rate capability and provided a larger surface area and short distance for ion diffusion, as well as electron transport. To investigate the resistance behaviors of the AS, Figure $5 \mathrm{c}$ displays the Nyquist plots fitted with Zview software by using an equivalent circuit model and the enlarged drawing of $R_{s}$ and $R_{c t}$. Obviously, the Nyquist plot showed a steep incline at low frequencies, which exhibited the good characteristics of the AS and small ion diffusion resistance in the electrolyte. As displayed in the inset image of Figure $5 \mathrm{c}$, the intercept of the trend curve on the horizontal coordinate was the value of the equivalent series resistance $\left(R_{s}\right)$ of AS, which was about $1.4 \Omega$. Particularly, the arc-shaped curve of the enlarged image at high frequency area represented the value of $R_{c t}$ and the typical pseudo-capacitive performance of AS. Finally, the electrochemical 
stability of the AS device was also tested by a long cycling life experiment at the current density of $2 \mathrm{~A} / \mathrm{g}$ up to 5000 times. As shown in Figure $5 \mathrm{~d}$, the one-sheet $\mathrm{ZnO} / \mathrm{CNT} / \mathrm{FP} / \mathrm{Fe}_{3} \mathrm{O}_{4} / \mathrm{CNT} / \mathrm{FP}$ AS device demonstrated a remarkable long-term cycling stability with $12.9 \%$ deterioration of the original specific capacitance value after 5000 times of a charge-discharge test, which can be ascribed to the mass loss of the as-prepared $\mathrm{ZnO} / \mathrm{CNT} / \mathrm{FP} / \mathrm{Fe}_{3} \mathrm{O}_{4} / \mathrm{CNT} / \mathrm{FP}$ materials in the electrolyte during the charge-discharge process. For flexibility, Figure 6 displays the specific capacitance retention of the circular AS (2 cm in diameter) changing with folding times under different folding degrees of $45^{\circ}, 90^{\circ}$, $135^{\circ}$ and $180^{\circ}$, respectively. Remarkably, the calculated specific capacitance retention rate still remained on a high level (87.3\%) even at the most frequently folding times of 1000 and maximum folding angle of $180^{\circ}$, respectively.
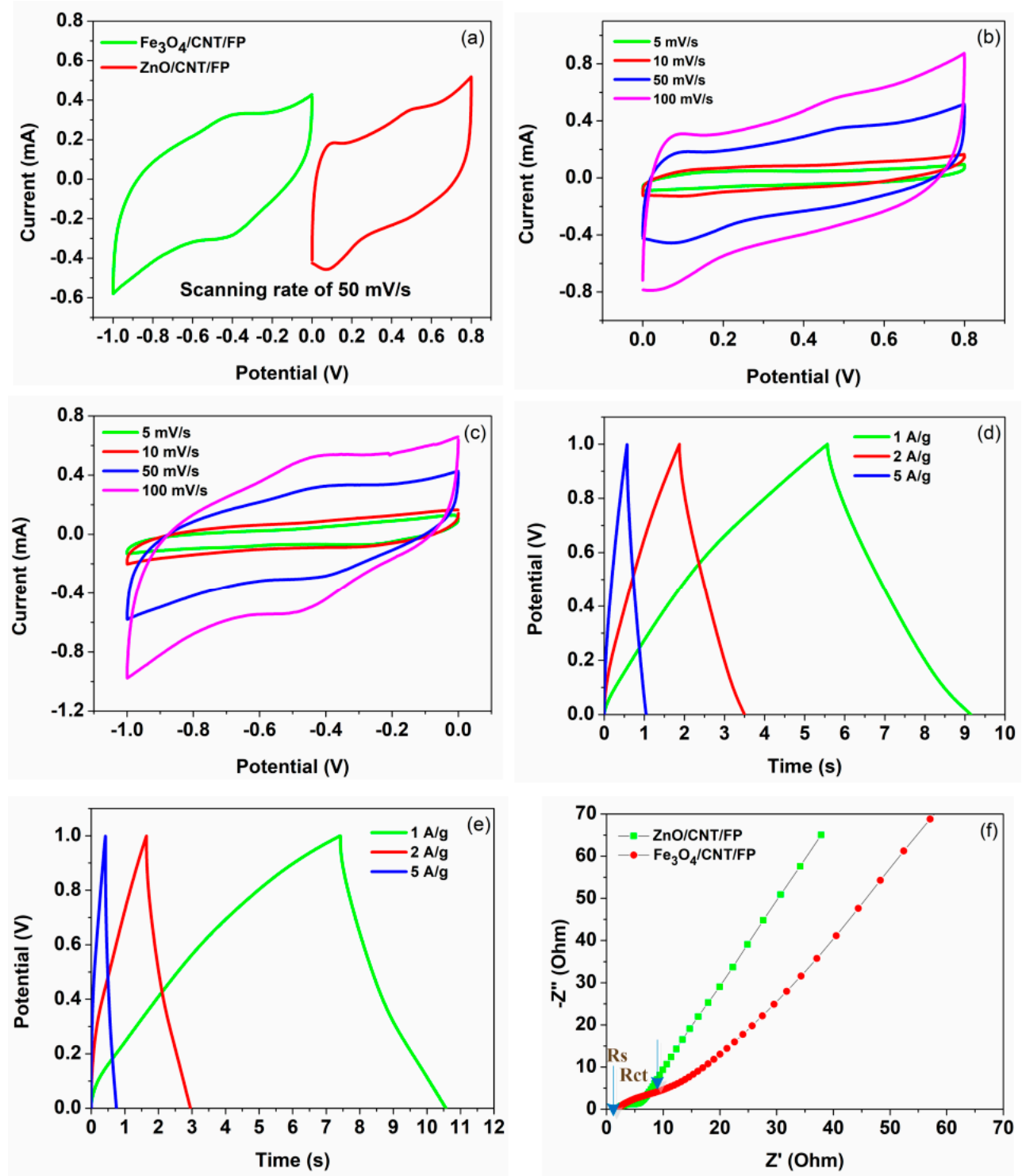

Figure 4. (a) Cyclic voltammetry (CV) curves of $\mathrm{ZnO} / \mathrm{CNT} / \mathrm{FP}$ and $\mathrm{Fe}_{3} \mathrm{O}_{4} / \mathrm{CNT} / \mathrm{FP}$ electrodes at the scanning rate of $50 \mathrm{mV} / \mathrm{s}$; (b) $\mathrm{CV}$ curves of $\mathrm{ZnO} / \mathrm{CNT} / \mathrm{FP}$ at different scanning rates; (c) $\mathrm{CV}$ curves of $\mathrm{Fe}_{3} \mathrm{O}_{4} / \mathrm{CNT} / \mathrm{FP}$ at different scanning rates; (d) galvanostatic charge/discharge (GCD) curves of the $\mathrm{ZnO} / \mathrm{CNT} / \mathrm{FP}$ electrode at different current densities; (e) GCD curves of the $\mathrm{Fe}_{3} \mathrm{O}_{4} / \mathrm{CNT} / \mathrm{FP}$ electrode at different current densities; (f) Nyquist plots of the $\mathrm{ZnO} / \mathrm{CNT} / \mathrm{FP}$ and $\mathrm{Fe}_{3} \mathrm{O}_{4} / \mathrm{CNT} / \mathrm{FP}$ electrodes, respectively. 

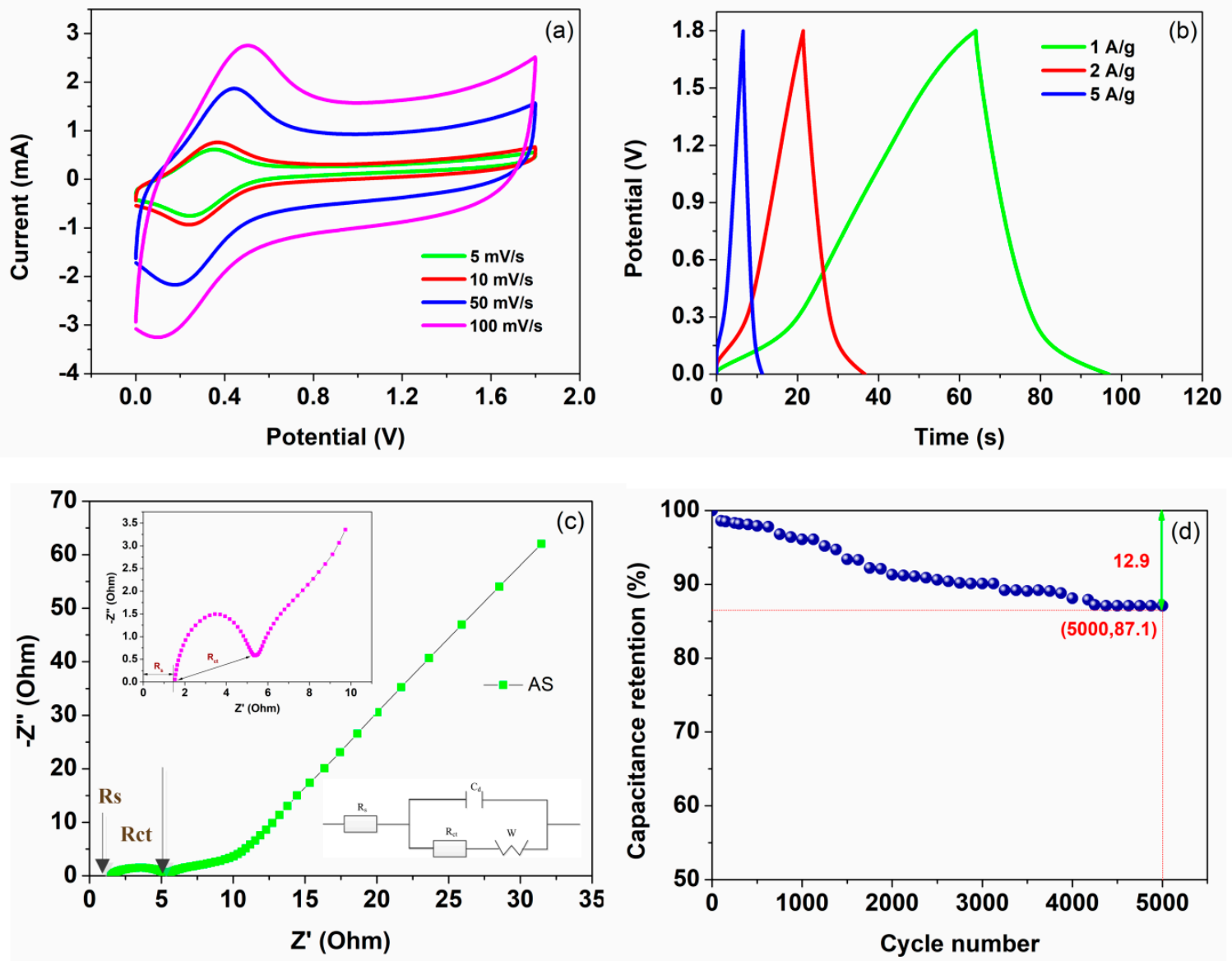

Figure 5. (a) CV curves of the AS at different scanning rates. (b) GCD curves of the AS at different current densities. (c) Nyquist plots of the AS. (d) Stability study for the AS.

Table 1. The specific capacitance, energy density and power density of the AS at different current densities.

\begin{tabular}{cccc}
\hline $\begin{array}{c}\text { Current Density } \\
\text { (A/g) }\end{array}$ & $\begin{array}{c}\text { Specific Capacitance } \\
(\mathbf{F} / \mathbf{g})\end{array}$ & $\begin{array}{c}\text { Energy Density } \\
\mathbf{( W ~ h / k g )}\end{array}$ & $\begin{array}{c}\text { Power Density } \\
\mathbf{( k W / k g})\end{array}$ \\
\hline 1 & 139.12 & 125.21 & 13.74 \\
2 & 129.00 & 116.11 & 27.48 \\
5 & 100.19 & 90.17 & 68.70 \\
\hline
\end{tabular}

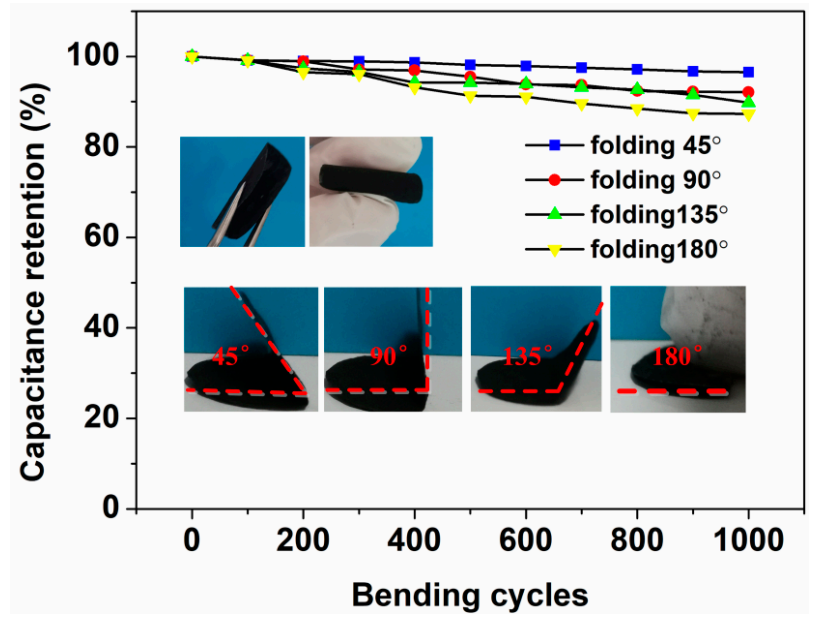

Figure 6. Capacitance retention of the AS at different folding degrees. 
Figure 7 below shows the digital and SEM images of the AS electrodes after bending. As it can be seen from the photographs, there was a sharp crease with $2 \mathrm{~cm}$ in length in the middle of the AS, which was equal to the diameter of the circular AS. To compare the changes of morphologies after folding, Figure 7a displayed the SEM image of the crack on the ZnO/CNT/FP electrode. After suffering from the repeated bending forces, the cellulose fibers of FP were destroyed and became discontinuous. But the electrochemical activities were still covered on the surface of each fiber, which prevented the rapid decline of the capacitance with the folding times increasing. However, the SEM image of cellulose fibers of the other electrode $\left(\mathrm{Fe}_{3} \mathrm{O}_{4} / \mathrm{CNT} / \mathrm{FP}\right)$ in Figure $7 \mathrm{~b}$ changed little after bending many times. The reason for this can be ascribed to the bending force acting directly on the electrode of $\mathrm{ZnO} / \mathrm{CNT} / \mathrm{FP}$, resulting in the different force condition on the two sides of the AS. Figure 8 shows the curve of capacitance retention over the scanning rates. Remarkably, the capacitance retention of the as-prepared AS reached $87.4 \%$ even at the highest scanning rate of $500 \mathrm{mV} / \mathrm{s}$. The excellent rate capability of the AS was attributed to the electrochemical activities on the surface and the reduced path of the electrolyte transport. A red LED light $(40 \mathrm{~mW})$ was lighted when it was connected to the fully charged power system (Figure 8 inset).
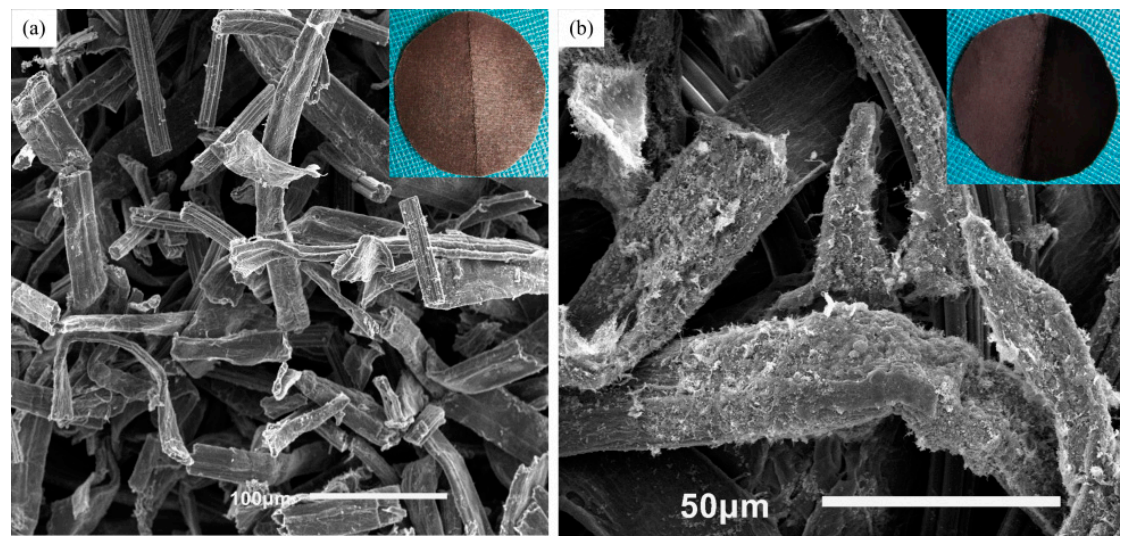

Figure 7. (a) SEM image of the AS electrode (ZnO/CNT/FP) after bending. (b) SEM image of the AS electrode $\left(\mathrm{Fe}_{3} \mathrm{O}_{4} / \mathrm{CNT} / \mathrm{FP}\right)$ after folding.

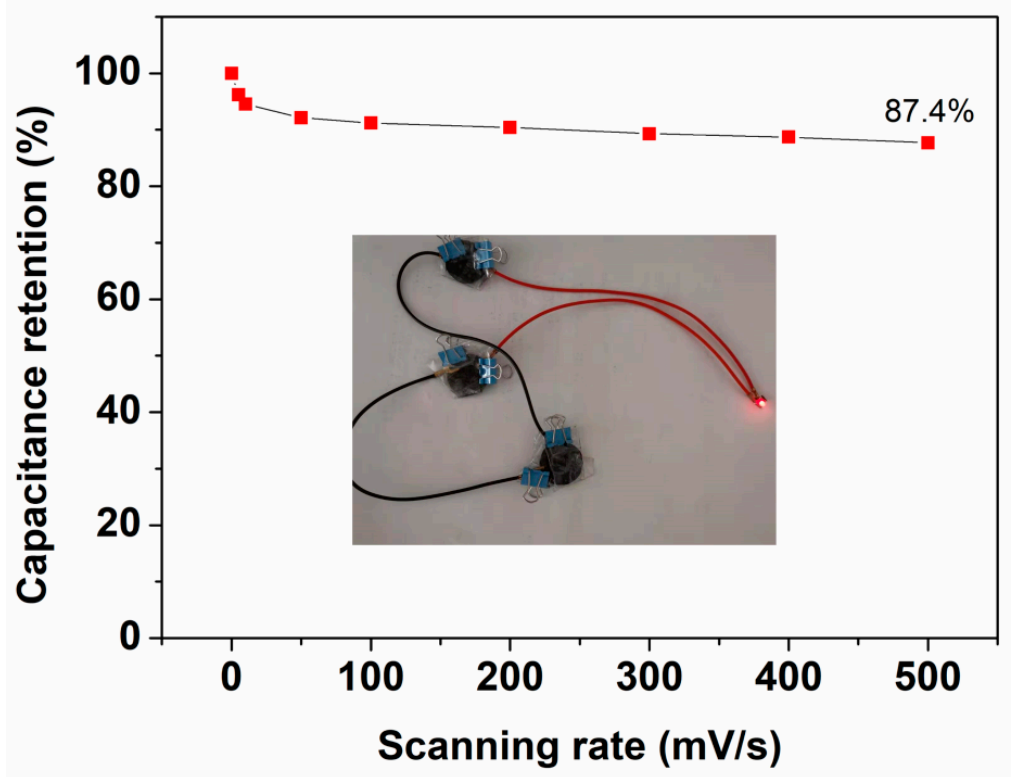

Figure 8. Rate stability of the AS and the application of powering the LED light (40 $\mathrm{mW})$. 


\section{Conclusions}

To summarize, a novel AS assembled on one-sheet of filter paper was synthesized by using a $\mathrm{ZnO} / \mathrm{CNT} / \mathrm{FP}$ nanocomposite as a positive electrode and $\mathrm{Fe}_{3} \mathrm{O}_{4} / \mathrm{CNT} / \mathrm{FP}$ as a negative electrode, respectively. The comparative results clearly revealed that this smart and pocket-sized device demonstrated superior electrochemical performances (specific capacitance, energy density, power density and cycling stability) in potential applications for AS. On the other hand, this paper provided a new and effective method for manufacturing the integrated supercapacitor without special preparation of a separator. The conducting coatings of CNTs and pseudo-capacitance of metal oxides effectively covered the two surfaces of the filter paper, creating about $150 \mu \mathrm{m}$ thick of interior layer, which was served as a separator of the one-sheet AS. These findings indicated that the as-prepared AS was considered to be a promising candidate as a high-performance, flexible electronic device. In addition, this kind of AS can be widely used in many fields, including energy storage and power output technologies for portable electronics, electric vehicles, and renewable energy systems operating on intermittent sources for the next generation.

Author Contributions: The work of conceptualization and formal analysis were accomplished S.J.; The work of funding acquisition, investigation and methodology were accomplished by T.L. and H.L. C.X. and T.Z. were responsible of supervision and validation. The work of analyzing the experimental data and matching work were done by C.T. and A.D.

Funding: This work was financially supported by National Natural Science Foundation of China (Grant No.51672221).

Acknowledgments: The authors wish to thank W.W. for advice on the experimental design and the timely help in analyzing the large number of samples.

Conflicts of Interest: No conflict of interest exits in the submission of this paper. The paper is approved by all authors for publication. I would like to declare on behalf of my co-authors that the work described is original research that has not been published previously, and not under consideration for publication elsewhere, in whole or in part. All the authors listed have approved the paper that is enclosed.

\section{References}

1. Borenstein, A.; Hanna, O. Carbon-based composite materials for supercapacitor electrodes: A review. J. Mater. Chem. A 2017, 5, 12653-12672. [CrossRef]

2. Zuo, W.; Li, R. Battery-Supercapacitor Hybrid Devices: Recent progress and future prospects. Adv. Sci. 2017, 4, 1600539. [CrossRef] [PubMed]

3. Zeng, Y.; Yu, M. Iron-based supercapacitor electrodes: Advances and Challenges. Adv. Energy Mater. 2016, 6, 1601053. [CrossRef]

4. Gao, Y.; Wang, Y. Removal of rhodamine B with Fe-supported bentonite as heterogeneous photo-fenton catalyst under visible irradiation. Appl. Catal. B Environ. 2015, 178, 29-36. [CrossRef]

5. Yang, Y.; Huang, Q. Waterproof, ultrahigh areal-capacitance, wearable supercapacitor fabrics. Adv. Mater. 2017, 29, 1606679. [CrossRef] [PubMed]

6. Libich, J.; Máca, J. Supercapacitors: Properties and applications. J. Energy Storage 2018, 17, 224-227. [CrossRef]

7. Redondo, E.; Carretero-González, J. Effect of pore texture on performance of activated carbon supercapacitor electrodes derived from olive pits. Electrochim. Acta 2015, 160, 178-184. [CrossRef]

8. Cao, J.; He, P. Supercapacitor electrodes from the in situ reaction between two-dimensional sheets of black phosphorus and graphene oxide. ACS Appl. Mater. Interfaces 2018, 10, 10330-10338. [CrossRef]

9. Ma, Y.; Chang, H. Graphene-based materials for lithium-ion hybrid supercapacitors. Adv. Mater. 2015, 27, 5296-5308. [CrossRef]

10. Xiong, C.; Li, B. The recent progress on three-dimensional porous graphene-based hybrid structure for supercapacitor. Compos. Part B Eng. 2019, 165, 10-46. [CrossRef]

11. Choi, C.; Sim, H.J. Elastomeric and dynamic $\mathrm{MnO}_{2} / \mathrm{CNT}$ core-Shell structure coiled yarn supercapacitor. Adv. Energy Mater. 2016, 6, 1502119. [CrossRef]

12. Xue, M.; Xie, Z. Microfluidic etching for fabrication of flexible and all-solid-state micro supercapacitor based on $\mathrm{MnO}_{2}$ nanoparticles. Nanoscale 2011, 3, 2703-2708. [CrossRef] [PubMed] 
13. Choudhary, N.; Li, C. Asymmetric supercapacitor electrodes and devices. Adv. Mater. 2017, $29,1605336$. [CrossRef] [PubMed]

14. Shown, I.; Ganguly, A. Conducting polymer-based flexible supercapacitor. Energy Sci. Eng. 2015, 3, 2-26. [CrossRef]

15. Jiang, L.; Sheng, L. Densely packed graphene nanomesh-carbon nanotube hybrid film for ultra-high volumetric performance supercapacitors. Nano Energy 2015, 11, 471-480. [CrossRef]

16. Liu, Z.; Yu, X.-Y. Etching-in-a-Box: A novel strategy to synthesize unique yolk-shelled $\mathrm{Fe}_{3} \mathrm{O}_{4} @$ carbon with an ultralong cycling life for lithium storage. Adv. Energy Mater. 2016, 6, 1502318. [CrossRef]

17. Godillot, G.; Taberna, P.L. High power density aqueous hybrid supercapacitor combining activated carbon and highly conductive spinel cobalt oxide. J. Power Sources 2016, 331, 277-284. [CrossRef]

18. Xiong, C.; Li, T.; Zhao, T.; Dang, A.; Ji, X.; Li, H.; Etesami, M. Three-dimensional graphene $/ \mathrm{MnO}_{2}$ nanowalls hybrid for high-efficiency electrochemical supercapacitors. Nano 2018, 13, 1850013. [CrossRef]

19. Zhi, M.; Xiang, C. Nanostructured carbon-metal oxide composite electrodes for supercapacitors: A review. Nanoscale 2013, 5, 72-88. [CrossRef]

20. Huang, G.; Zhang, Y. Fiber-based $\mathrm{MnO}_{2}$ /carbon nanotube/polyimide asymmetric supercapacitor. Carbon 2017, 125, 595-604. [CrossRef]

21. Salunkhe, R.R.; Zakaria, M.B. Fabrication of asymmetric supercapacitors based on coordination polymer derived nanoporous materials. Electrochim. Acta 2015, 183, 94-99. [CrossRef]

22. Yang, G.; Park, S.-J. Facile hydrothermal synthesis of $\mathrm{NiCo}_{2} \mathrm{O}_{4}$-decorated filter carbon as electrodes for high performance asymmetric supercapacitors. Electrochim. Acta 2018, 285, 405-414. [CrossRef]

23. Afzal, A.; Abuilaiwi, F.A. Polypyrrole/carbon nanotube supercapacitors: Technological advances and challenges. J. Power Sources 2017, 352, 174-186. [CrossRef]

24. Cao, X.; Zheng, B. Reduced graphene oxide-wrapped $\mathrm{MoO}_{3}$ composites prepared by using metal-organic frameworks as precursor for all-solid-state flexible supercapacitors. Adv. Mater. 2015, 27, 4695-4701. [CrossRef]

25. Zhao, W.; Wang, S. Double polymer sheathed carbon nanotube supercapacitors show enhanced cycling stability. Nanoscale 2016, 8, 626-633. [CrossRef] [PubMed]

26. Lang, A.W.; Ponder, J.F. Flexible, aqueous-electrolyte supercapacitors based on water-processable dioxythiophene polymer/carbon nanotube textile electrodes. J. Mater. Chem. A 2017, 5, 23887-23897. [CrossRef]

27. Lee, K.M.; Lai, C.W. Recent developments of zinc oxide based photocatalyst in water treatment technology: A review. Water Res. 2016, 88, 428-448. [CrossRef]

28. Bhuyan, T.; Mishra, K.; Khanuja, M.; Prasad, R.; Varma, A. Biosynthesis of zinc oxide nanoparticles from Azadirachta indica for antibacterial and photocatalytic applications. Mater. Sci. Semicond. Proc. 2015, 32, 55-61. [CrossRef]

29. Kumar, S.; Ahlawat, W. Graphene, carbon nanotubes, zinc oxide and gold as elite nanomaterials for fabrication of biosensors for healthcare. Biosens. Bioelectron. 2015, 70, 498-503. [CrossRef]

30. Lo, I.H.; Wang, J.-Y. Synthesis of $\mathrm{Ni}(\mathrm{OH})_{2}$ nanoflakes on $\mathrm{ZnO}$ nanowires by pulse electrodeposition for high-performance supercapacitors. J. Power Sources 2016, 308, 29-36. [CrossRef]

31. $\mathrm{Li}, \mathrm{T}$; $\mathrm{Bai}, \mathrm{X} . \mathrm{Fe}_{3} \mathrm{O}_{4}$ nanoparticles decorated on the biochar derived from pomelo pericarp as excellent anode materials for Li-ion batteries. Electrochim. Acta 2016, 222, 1562-1568. [CrossRef]

32. Ye, Y.; Kong, T. Enhanced nonenzymatic hydrogen peroxide sensing with reduced graphene oxide/ferroferric oxide nanocomposites. Talanta 2012, 89, 417-421. [CrossRef] [PubMed]

33. Xia, T.; Xu, X. Facile complex-coprecipitation synthesis of mesoporous $\mathrm{Fe}_{3} \mathrm{O}_{4}$ nanocages and their high lithium storage capacity as anode material for lithium-ion batteries. Electrochim. Acta 2015, 160, 114-122. [CrossRef]

34. Sun, J.; Zan, P. Room-temperature synthesis of $\mathrm{Fe}_{3} \mathrm{O}_{4} / \mathrm{Fe}$-carbon nanocomposites with Fe-carbon double conductive network as supercapacitor. Electrochim. Acta 2016, 215, 483-491. [CrossRef]

35. Chang, B.; Guo, Y. Hierarchical porous carbon derived from recycled waste filter paper as high-performance supercapacitor electrodes. RSC Adv. 2015, 5, 72019-72027. [CrossRef]

36. Zhang, L.; Zhu, P. Flexible Asymmetrical Solid-State Supercapacitors based on laboratory filter paper. ACS Nano 2016, 10, 1273-1282. [CrossRef] [PubMed] 
37. Liu, Z.; Wang, D.; Tang, Z.; Liang, G.; Yang, Q.; Li, H.; Ma, L.; Mo, F.; Zhi, C. A mechanically durable and device-level tough $\mathrm{Zn}-\mathrm{MnO}_{2}$ battery with high flexibility. Energy Storage Mater. 2019. [CrossRef]

38. Wang, Y.; Chen, F.; Liu, Z.; Tang, Z.; Yang, Q.; Zhao, Y.; Du, S.; Chen, Q.; Zhi, C. A Highly Elastic and Reversibly Stretchable All-polymer Supercapacitor. Angew. Chem. Int. Ed. 2019. [CrossRef]

39. Liu, A.; Kovacik, P. Monolithic flexible supercapacitors integrated into single sheets of paper and membrane via vapor printing. Adv. Mater. 2017, 29, 1606091. [CrossRef]

40. Xia, C.; Jiang, Q. Asymmetric supercapacitors with metal-like ternary selenides and porous graphene electrodes. Nano Energy 2016, 24, 78-86. [CrossRef]

41. Gao, Z.; Yang, W. Flexible all-solid-state hierarchical $\mathrm{NiCo}_{2} \mathrm{O}_{4} /$ porous graphene paper asymmetric supercapacitors with an exceptional combination of electrochemical properties. Nano Energy 2015, 13, 306-317. [CrossRef]

42. Xiong, C.; Li, T. Two-step approach of fabrication of three-dimensional $\mathrm{MnO}_{2}$-graphene-carbon nanotube hybrid as a binder-free supercapacitor electrode. J. Power Sources 2016, 306, 602-610. [CrossRef]

43. Arod, P.; Shivashankar, S.A. Single-step synthesis of carbon nanotubes/iron/iron oxide composite films through inert-ambient CVD using ferric acetylacetonate as a precursor. RSC Adv. 2015, 5, 59463-59471. [CrossRef]

44. Kim, C.H.; Kim, B.-H. Zinc oxide/activated carbon nanofiber composites for high-performance supercapacitor electrodes. J. Power Sources 2015, 274, 512-520. [CrossRef]

45. Sreejesh, M.; Dhanush, S. Microwave assisted synthesis of $\mathrm{rGO} / \mathrm{ZnO}$ composites for non-enzymatic glucose sensing and supercapacitor applications. Ceram. Int. 2017, 43, 4895-4903. [CrossRef]

46. Li, J.; Sun, Y. Novel ternary composites reduced-graphene oxide/zine oxide/poly(p-phenylenediamine) for supercapacitor: Synthesis and properties. J. Alloys Compd. 2017, 708, 787-795. [CrossRef]

(C) 2019 by the authors. Licensee MDPI, Basel, Switzerland. This article is an open access article distributed under the terms and conditions of the Creative Commons Attribution (CC BY) license (http://creativecommons.org/licenses/by/4.0/). 